\title{
Large borderline phyllodes breast tumor related to histopathology, diagnosis, and treatment management - case report
}

\author{
Nicolae OVidiu Peneş ${ }^{1,2)}$, Anca LuCia PoP3), Roxana Georgiana Borşş), Valentin Nicolae Varlas ${ }^{2,4)}$ \\ 1) Department of Anesthesiology and Intensive Care, Bucharest University Emergency Hospital, Bucharest, Romania \\ 2) Carol Davila University of Medicine and Pharmacy, Bucharest, Romania \\ 3) Department of Clinical Laboratory, Carol Davila University of Medicine and Pharmacy, Bucharest, Romania \\ 4) Department of Obstetrics and Gynecology, Filantropia Clinical Hospital, Bucharest, Romania
}

\begin{abstract}
Breast phyllodes tumors (PTs) are uncommon tumors with a biphasic fibroepithelial component, characterized by rapid development in middleaged women. A correct preoperative diagnosis after Tru-Cut biopsy allows for proper surgical planning. The treatment of choice remains surgery (wide local excision or mastectomy) with or without breast reconstruction, depending on the size and histopathological (HP) nature of the tumor. We reported a case of a 50-year-old woman with a large PT in her left breast, measuring $11 / 10 \mathrm{~cm}$. Preoperative HP examination revealed biphasic proliferation, with the appearance of benign PT. The patient underwent a left mastectomy, with a favorable postoperative evolution. The final HP diagnosis was borderline PT, with areas of lipomatous metaplasia. After three months, breast reconstruction was performed. The therapeutic management of large PTs continues to be a challenge for pathologists and surgeons. Due to the increased frequency of local recurrence and HP progression to malignancies, the treatment of choice for these patients is mastectomy, without lymphadenectomy.
\end{abstract}

Keywords: phyllodes tumor, histopathology, breast tumor, diagnosis, treatment.

\section{Introduction}

According to the World Health Organization (WHO) recommendations, phyllodes tumors (PTs) have a spectrum with a high degree of polymorphism being classified histopathologically as benign, borderline, or malignant. They represent a continuous attempt by pathologists, medical imaging specialists, and surgeons [1].

The incidence of PT is maximum in women aged between 35 and 55 years. The percentage of borderline PT varies from $12 \%$ to $26 \%$, and the local recurrence rate is $14-25 \%$ [2].

PT has a broad spectrum of morphology, and sometimes, the boundaries are not clearly distinguished between PT and fibroadenomas $[2,3]$. Thus, an essential role is played by histopathological (HP) evaluation with the emergence of well-defined HP criteria that can lead to an accurate diagnosis and after a therapeutic correlation. Genomic sequencing of PT will be an alternative to improve the diagnosis and early identification of the evolution of these tumors to malignant forms [3].

The non-specific clinical picture and HP elements can sometimes be inconclusive. These factors can determine a high rate of diagnostic errors between fibroadenoma and PTs and between forms of PTs [4].

The diagnosis of PT requires the presence of both epithelium and stroma on biopsy samples. The stromal component determines the HP differentiation, benign PT having a rate of $<5$ mitoses $/ 10$ high-power fields (HPFs), as opposed to malignant ones with a rate higher than
10 mitoses/10 HPFs. Areas with hyalinosis or myxoid degeneration have also been described $[5,6]$.

The classification of PTs in the border area represents a risky staging in terms of the subsequent evolution of the case. These HP forms of borderline PT may have moderate and/or atypical stromal cellularity, an increased rate of mitosis, and a local mosaic of circumscribed or invasive areas. The precise HP classification of this form has not been resolved, Zhang \& Kleer stating that moderate stromal cellularity, nuclear atypia, and infiltrative areas may also be found in benign cases [3]. Mitotic activity is an essential parameter for tumor classification, a future role being correlated with molecular aspects.

The clinical significance of PT grading is to predict clinical behavior: benign tumors have the potential for local recurrence; borderline tumors have the potential for local recurrence and have a very low risk of metastasis. Malignant tumors have the highest risk of metastasis, which can be fatal [7].

Early diagnosis and appropriate treatment can improve the evolution, the result, and the quality of life. According to breast cancer screening guidelines, a routine mammogram is recommended for women over the age of 40 , especially for those with the rapid growth of the tumor within one year of initial detection.

\section{Aim}

The authors report the diagnostic and therapeutic challenge of a large borderline PT through pathologist

This is an open-access article distributed under the terms of a Creative Commons Attribution-NonCommercial-ShareAlike 4.0 International Public License, which permits unrestricted use, adaptation, distribution and reproduction in any medium, non-commercially, provided the new creations are licensed under identical terms as the original work and the original work is properly cited. 
and surgeon as well. Informed consent was obtained from subject involved in the study. The patient was apprised and signed the enrollment and publication agreement.

\section{Case presentation}

We present the case of a 50-year-old Caucasian woman diagnosed in 2014 with a left mammary tumor located in the superior-external quadrant, ultrasound (US) suspect breast imaging-reporting and data system (BI-RADS) 4B, with maximum diameters of 4.8/3.6/2.8 cm. The patient refused further investigation at that time. A breast US was performed two years later, which showed the same tumor in the left breast, with a bumpy structure, and dimensions of 5/4.4/3.5 cm, suggestive for the PT, BI-RADS 3 . Mammography showed a nodular opacity of $6.5 / 4.5 \mathrm{~cm}$, lobular, well-defined BI-RADS 2.3. In this case, the initial recommendation four years ago was to perform a lumpectomy, but the patient refused the surgical procedure. The patient neglected the diagnosis and periodic monitoring recommended.

In September 2020, four years later, the patient presented for reevaluation of the tumor mass, that rapid growth in the last weeks. The clinical examination showed a left breast tumor in external quadrants, of approximately $11 / 10 \mathrm{~cm}$, with irregular lobed contour, of hard consistency, with erythematous skin. Left axillary lymphadenopathy of approximately $1.8 / 1 \mathrm{~cm}$ was also identified (Figure 1, A and B).
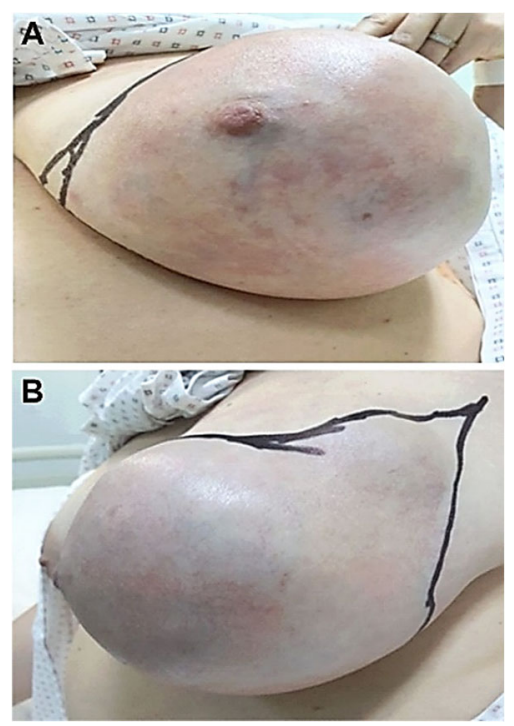

Figure 1 - Clinical examination revealed a large phyllodes tumor in the left breast: front image $(A)$ and lateral image $(B)$.

Breast US revealed an inhomogeneous, solid-appearing, and irregularly shaped tumor, with non-circumscribed margins, a decreased blood flow signal on Doppler, about $11 / 8 \mathrm{~cm}$ (Figure 2A).

Subsequently, the patient performed a chest computed tomography (CT) with a contrast substance that showed a macronodular lesion of $11.8 / 10 / 9 \mathrm{~cm}$, arranged at the external quadrants of the left breast, extended from the superficial level to $1 \mathrm{~cm}$ by the pectoralis muscle, which deforms the contour of the breast, iodophilic, with lobed contours and inhomogeneous structure by the presence of spontaneous hyperdense areas, necrotic inclusions and microcalcifications. Lymph node images were described intramammary, axillary (the station I), and retro-mammary, with dimensions less than $2 \mathrm{~cm}$ (Figure 2B).
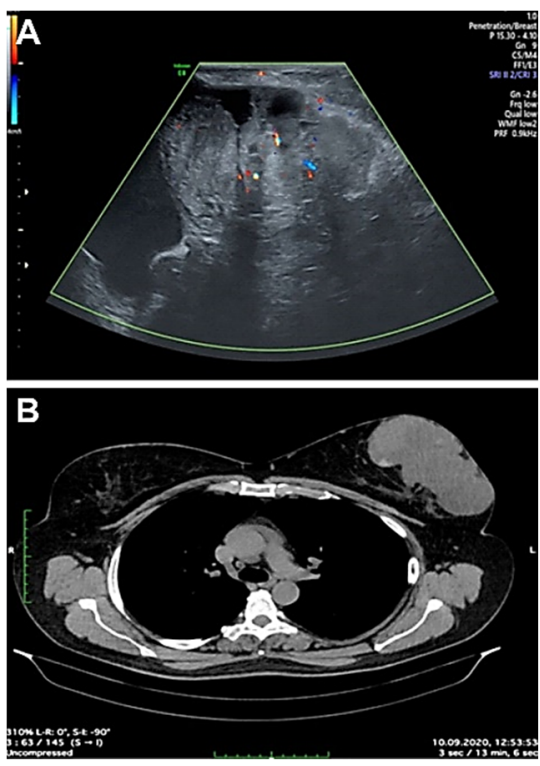

Figure 2 - Ultrasonography of the left breast revealed an enlargement of the breast, with a mixed echostructure and a decreased blood flow signal on Doppler (A). The $C T$ of the left breast showing a mass that is not invading the adjacent structures (B). CT: Computed tomography.

In October 2020, a Tru-Cut biopsy was performed on the left breast. HP appearance of the examined fragments was compatible with the diagnosis of biphasic proliferation with the aspect of benign PT.

The patient underwent a left mastectomy and excision of the left axillary lymphadenopathy in November 2020. Intraoperatively, a tumor fragment was sent for extemporaneous analysis and revealed PT and area of lobular adenomatous hyperplasia. Final surgical HP examination revealed borderline PT and peritumoral lobular adenomatous hyperplasia. Three ganglia with diffuse sclerosis were identified in the left axillary adenopathy block (Figure 3, $\mathrm{A}$ and $\mathrm{B}$ ).

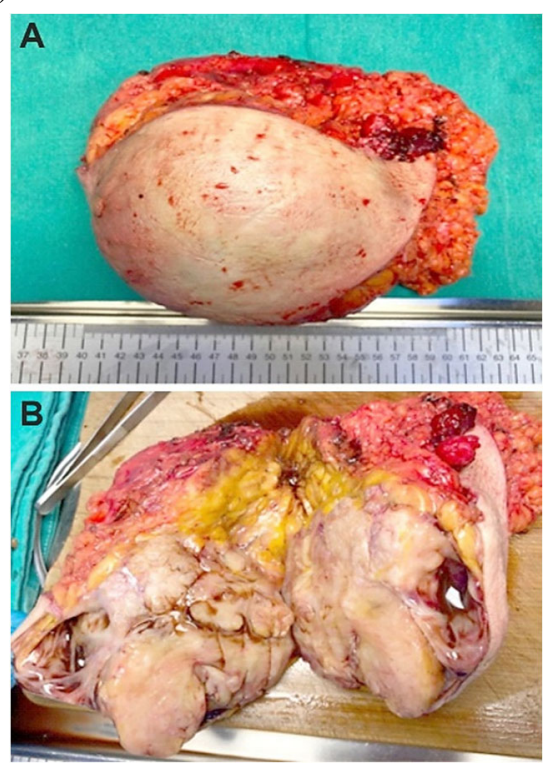

Figure 3 - Left mastectomy specimen measuring $18 / 17 / 5 \mathrm{~cm}$ (A). Tumor mass of $10 \mathrm{~cm}$, well defined, fibromatous, with areas of necrosis and hemorrhages (B). 
Sections showed in the framework of tumor fibroepithelial proliferation, with a predominance of the stromal component, variable cell density, relatively well-demarcated at the periphery, mitotic index of 4 mitoses/10 HPFs, with areas of lipomatous metaplasia and pseudoangiomatous stromal hyperplasia (PASH), hemorrhages, and hemorrhagic necrosis, moderate chronic interstitial inflammatory infiltrate, and areas with moderate typical ductal hyperplasia (Figure 4, A-F).
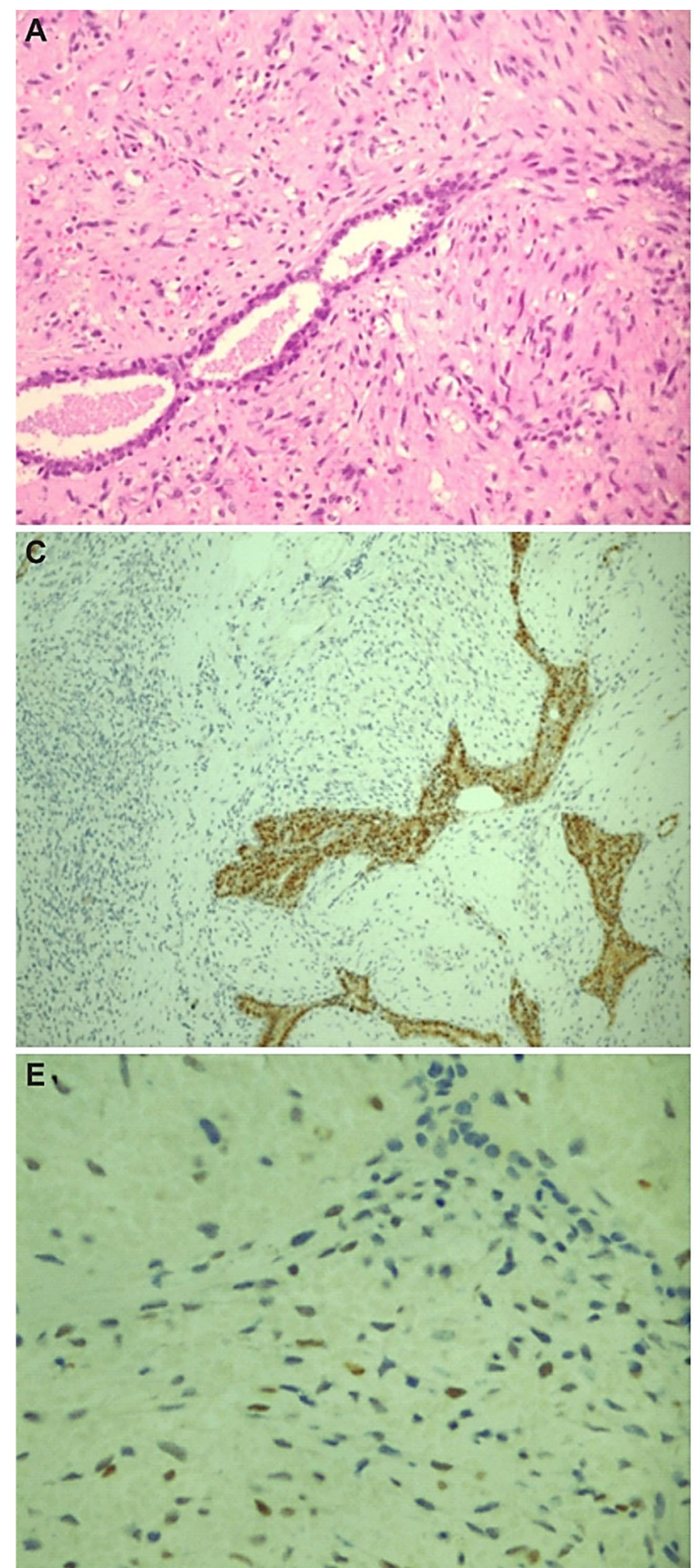

Immunohistochemical examination was carried out and showed positivity in tumor cells in the epithelial component for E-cadherin and estrogen receptors (ERs) $(55 \%)$ (Figure 4C). p53 was positive in approximately 35\% of tumor cells in the stromal component, with a mosaic pattern (Figure 4E). In tumor cells from the stromal component, cluster of differentiation (CD)34 was zonal positive (Figure 4B) and Ki67 was positive in $15 \%$ of cells (Figure 4D). CD34 was also positive in vessels.
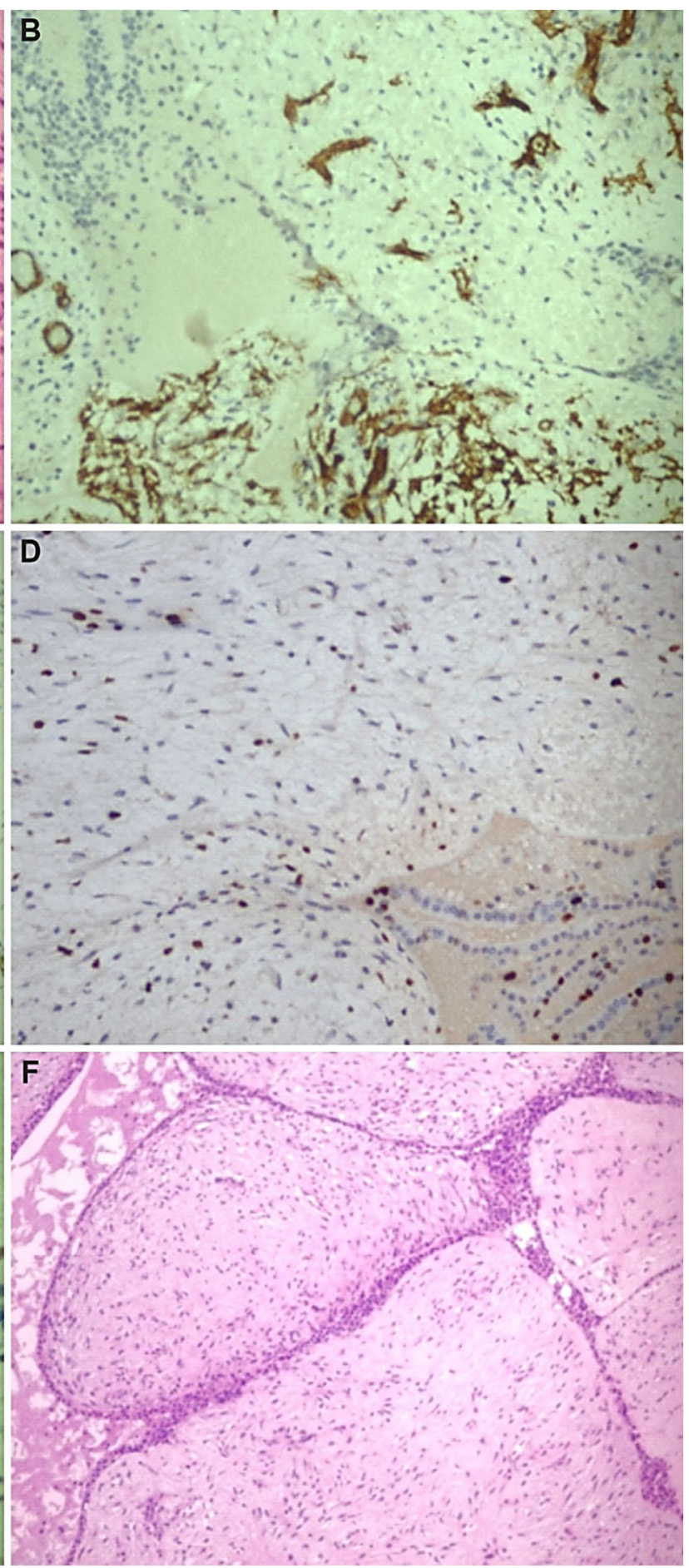

Figure 4-IHC analysis of the left breast revealed: (A) Detail with "leaf-like" epithelial structures; (B) CD34-positive reaction in vessels and stromal cells, negative reaction in epithelial cells $(\times 100)$; (C) IHC staining for ERs, positive reaction in epithelial cell nuclei $(\times 100)$; (D) Ki67 positive in both stromal and epithelial cells, in a proportion of approximately 20\% ( $\times 200)$; (E) p53 positive in approximately 35\% of stromal cells, negative in epithelial cells $(\times 400) ;(F)$ The area with a fibroadenomatoid appearance, with ducts flattened in deer antlers. HE staining: $(A) \times 200 ;(F) \times 100$. CD34: Cluster of differentiation 34; ERs: Estrogen receptors; HE: Hematoxylin-Eosin; IHC: Immunohistochemical. 
The patient had good postoperative recovery. At three months after mastectomy, deep inferior epigastric perforator (DIEP) flap breast reconstruction was performed in a Plastic Surgery Department. The reconstruction was performed with autologous abdominal graft. In one month, the patient is scheduled for the second plastic surgery for the nipple reconstruction and mammaplasty of the right breast for symmetry (Figure 5, A and B). At seven-month follow-up, there are no signs of recurrence of the lesions on clinical or US examination.

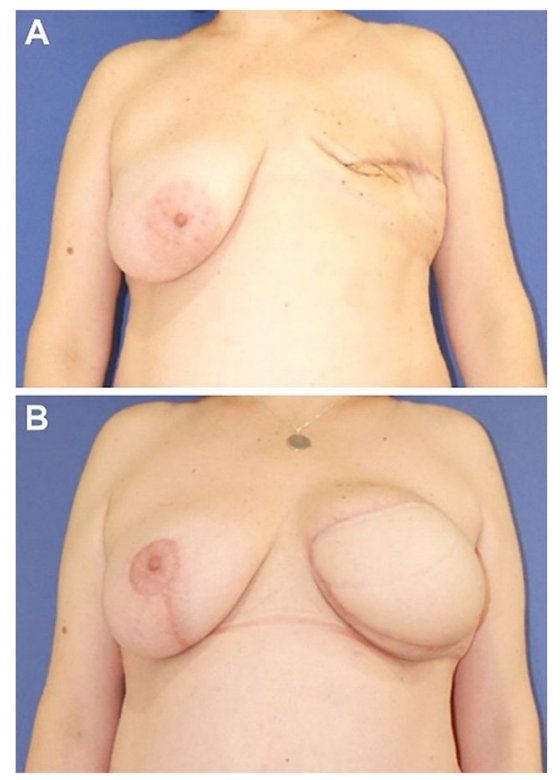

Figure 5 - (A) Patient at three months postoperative. (B) Result of DIEP flap breast reconstruction. DIEP: Deep inferior epigastric perforators.

\section{口 Discussions}

PTs are a rare complex group of fibroepithelial mammary lesions with uncertain behavior. We search on the PubMed database (10-year topic), screening for the MeSH keyword "phyllodes breast tumor", and found only three randomized clinical trial (RCT)/controlled trial reports, which represented scarce data despite a continuous interest in this pathology.

The classification proposed by the $W H O$ of PTs as benign, borderline, or malignant is based on HP criteria that include stromal cellularity, cellular atypia, and the frequency of mitosis. Most tumors are benign, being found in $60-75 \%$ of cases, while malignant tumors in only 10 $20 \%$. Borderline tumors are found in $13-26 \%$ of cases $[3,6,8]$.

The PT on US examination or mammography may present as a large, lobed, well-defined mass with a higher density than the adjacent tissue. A clear halo around the tumor due to rapid growth cannot distinguish the tumor from a fibroadenoma or differentiate between the three types of PT. Irregular shape, the appearance of cysts, diameter $>3 \mathrm{~cm}$, tilts the diagnosis to the borderline or malignant PT. On examination of CT or magnetic resonance imaging (MRI), suggestive signs for PT consist in the appearance in cystic hemorrhagic spaces of solid portions, with greater intensification [9].

Tan et al. showed the usefulness of US and MRI to determine preoperatively the HP degree of breast PT, initially recommending MRI in case of a fast-growing and painless breast tumor formation $[10,11]$.

The final diagnosis is HP by analyzing the excised breast tissue. The benign PT has clinic, imagistic, or macroscopic characteristics that overlap with breast fibroadenoma. PT has slightly increased stromal cellularity compared to a fibroadenoma, minimal nuclear atypia, and $\leq 4$ mitoses/10 HPFs.

Malignant PT can be easily confused with primary breast sarcoma or metaplastic carcinoma with spindleshaped cells, has stromal hypercellularity and marked atypia. Furthermore, has the mitotic activity of at least 10 mitoses/10 HPFs, infiltrative-expansive growth, and the presence of large necrohemorrhagic areas.

Borderline PT have intermediate characteristics. The borderline PT has larger atypia than the benign tumor, circumscribed or invasive focused border, a mitotic index between 5-9 mitoses/10 HPFs, and moderate stromal cellularity, with possible areas of hemorrhage and necrosis. The size, appearance of borderline and areas of lipomatous metaplasia described in this study are aspects rarely present in these tumors and may represent an original appearance. Thus, Pornchai et al. revealed that pure lipomatous differentiation is very rare [12].

Macro and microscopic hemorrhage were observed in borderline and malignant forms, and tumor necrosis was frequently found in malignant forms [13]. Areas of infarction or tumor necrosis may be elements mainly in large formations that correlate with the type of PT and the potential for recurrence. The mechanisms underlying this evolution are represented by cell turnover, cell apoptosis, and vascular pattern. Mitotic activity is an essential parameter among HP features to diagnose borderline tumors.

The prediction regarding the degree and prognosis of PT aimed to identify specific markers of immunohistochemistry. Ki67 immunostaining is observed in 3\% of normal breast epithelial cells, $25 \%$ in benign PT and $15-$ $100 \%$ in malignant PT [14].

In particular, in the case of malignant forms of PT was observed an association of p53 immunomarker and Ki67 proliferative tumor suppressors, due to an increased rate of cellular mitosis and certain HP features.

Furthermore, the association of Ki67 with p53 is useful in identifying forms of malignant PT, without being predictable regarding PT recurrence. The positivity of Ki67 and ERs increases the suspicion of borderline or malignant forms [15]. Other target markers have been linked to hormone receptors, angiogenesis (CD31) or epidermal growth factors (CD117, CD10) [14, 16]. Differentiation of sarcomas can be achieved by following the expression of the Ki67 proliferation index together with CD34 positive in the stroma $[17,18]$.

Recent molecular sequencing studies on the pathogenesis of fibroepithelial lesions have shown tumor progression pathways, highlighting recurrent mutations of the mediator complex subunit 12 (MED12) exon [19, 20]. Other studies reported other possible mutations in tumor pathogenesis, such as filamin A $(F L N A)$, retinoic acid receptor alpha $(R A R A)$, SET domain containing 2, histone lysine methyltransferase (SETD2), lysine methyltransferase 2D (KMT2D), retinoblastoma $1(R B 1)$, and epidermal growth factor receptor $(E G F R)[13,21]$. Chang et al., in 2020, focused 
on the top three mutations in fibroepithelial tumors: $M E D 12$, telomerase reverse transcriptase (TERT), and RARA [22].

PT treatment is exclusively surgical and consists of various procedures: wide local excision and total mastectomy. Usually, large local excision would be preferred in benign forms of PT. In borderline forms, surgical treatment varies depending on the volume of the tumor relative to the size of the breast, the possibility of having negative safety margins at the periphery of the tumor, between a conservative treatment (wide local excision) and a radical treatment (simple mastectomy).

According to guidelines for breast cancer, surgical treatment of PTs with a diameter $>3 \mathrm{~cm}$ involves a surgical excision within oncological safety limits regardless of the anatomical-clinical form; the recurrence rate is $16 \%$ in case of non-compliance with this limit $(<1 \mathrm{~cm})$ [23]. There was no agreement on the appropriate surgical margin to ensure complete excision and reduced risk of recurrence. Axillary lymph dissection is not routine, being reserved for patients with palpable lymph nodes detected preoperatively or with voluminous formations in which sentinel node biopsy is recommended.

Wang et al. indicated total mastectomy in patients whose tumor formations exceed $8 \mathrm{~cm}$ (benign or borderline), without negative resection margins, with malignant forms of PT or local recurrence $>3$ tumors [24]. In malignant forms of PT, mastectomy is the only option $[25,26]$.

In fact, in borderline and malignant forms, mastectomy decreased the rate of local recurrences and improved survival [25]. Choi et al. in a multicenter study, observed a similar evolution between mastectomy and wide local excision associated with radiotherapy. Although the guidelines do not clearly specify the conditions for performing a mastectomy in PT, there is still a consensus in patients over 50 years of age, with tumors $>5 \mathrm{~cm}$ or at increased risk of recurrence [24, 27]. In our patient, mastectomy was preferred due to the increased tumor volume in relation to the breast and the local risk of recurrence.

Unlike radiotherapy, postoperative chemotherapy and endocrine therapy did not decrease the local recurrence rate $[28,29]$. The prognosis of patients with PT is correlated with the anatomopathological form and the type of surgical procedure. PTs have a local recurrence potential of 3.6$8 \%$ for benign tumors, $14 \%$ for borderline tumors, and $30-42 \%$ for malignant ones. The recurrence rate is higher in the first two years after surgery. Metastasis occurs hematogeneously, most often in the lungs or bones. Metastasis rates are $<1 \%$ for benign tumors, $1.6 \%$ for borderline tumors, and increase to $16-22 \%$ for malignant tumors $[2,30]$. The overall five-year disease-free survival rate of PT ranged from $78 \%$ to $91 \%[15,24]$.

\section{ㅁ Conclusions}

PTs continue to be a diagnostic, HP, and surgical challenge, due to the low incidence of this type of tumor and due to the anatomical-clinical polymorphism. Large forms are associated with a relatively high risk of local recurrence that often involves surgical radicalism, with psychoemotional impact on patients. Due to the clinical and HP diversity encountered in PT, therapeutic management and clinical prognosis are still dependent on the accuracy of HP information. PT borderline continues to arouse the greatest interest, this will be clarified by further research for better PT management.

\section{Conflict of interests}

The authors declare no conflict of interests.

\section{Acknowledgments}

The authors would like to gratefully acknowledge Professor Carmen Maria Ardeleanu, MD, PhD for help with generating scanning images used in this paper.

\section{References}

[1] Rayzah M. Phyllodes tumors of the breast: a literature review. Cureus, 2020, 12(9):e10288. https://doi.org/10.7759/cureus. 10288 PMID: 32923300 PMCID: PMC7478785

[2] Rodrigues MF, Truong PT, McKevitt EC, Weir LM, Knowling MA, Wai ES. Phyllodes tumors of the breast: The British Columbia Cancer Agency experience. Cancer Radiother, 2018, 22(2): 112-119. https://doi.org/10.1016/j.canrad.2017.08.112 PMID: 29523388

[3] Zhang Y, Kleer CG. Phyllodes tumor of the breast: histopathologic features, differential diagnosis, and molecular/genetic updates. Arch Pathol Lab Med, 2016, 140(7):665-671. https:// doi.org/10.5858/arpa.2016-0042-RA PMID: 27362571

[4] Tan PH, Ellis I, Allison K, Brogi E, Fox SB, Lakhani S, Lazar AJ, Morris EA, Sahin A, Salgado R, Sapino A, Sasano H, Schnitt S, Sotiriou C, van Diest P, White VA, Lokuhetty D, Cree IA; WHO Classification of Tumours Editorial Board. The 2019 World Health Organization Classification of Tumours of the Breast. Histopathology, 2020, 77(2):181-185. https://doi.org/10.1111/ his.14091 PMID: 32056259

[5] Kim S, Kim JY, Kim DH, Jung WH, Koo JS. Analysis of phyllodes tumor recurrence according to the histologic grade. Breast Cancer Res Treat, 2013, 141(3):353-363. https://doi. org/10.1007/s10549-013-2684-x PMID: 24062207

[6] Garlet BB, Zogbi L, Lima JP, Favalli PPS, Krahe FD. Recurrent borderline phyllodes tumor of the breast submitted to mastectomy and immediate reconstruction: case report. Int J Surg Case Rep, 2019, 60:25-29. https://doi.org/10.1016/j.jjscr.2019.05.032 PMID: 31195364 PMCID: PMC6562175

[7] Pătraşcu A, Popescu CF, Pleşea IE, Bădulescu A, Tănase F, Mateescu G. Clinical and cytopathological aspects in phyllodes tumors of the breast. Rom J Morphol Embryol, 2009, 50(4): 605-611. PMID: 19942954

[8] Jabeen D, Vohra LM Sr, Siddiqui T, Raza AUN. Recurrent phyllodes tumour of the breast transforming to a fibrosarcoma. Cureus, 2020, 12(3):e7457. https://doi.org/10.7759/cureus. 7457 PMID: 32351836 PMCID: PMC7187999

[9] Venter AC, Roşca E, Daina LG, Muţiu G, Pirte AN, Rahotă D. Phyllodes tumor: diagnostic imaging and histopathology findings. Rom J Morphol Embryol, 2015, 56(4):1397-1402. PMID: 26743286

[10] Tan H, Zhang S, Liu H, Peng W, Li R, Gu Y, Wang X, Mao J, Shen $X$. Imaging findings in phyllodes tumors of the breast. Eur J Radiol, 2012, 81(1):e62-e69. https://doi.org/10.1016/ j.ejrad.2011.01.085 PMID: 21353414

[11] Foxcroft LM, Evans EB, Porter AJ. Difficulties in the preoperative diagnosis of phyllodes tumours of the breast: a study of 84 cases. Breast, 2007, 16(1):27-37. https://doi.org/10. 1016/j.breast.2006.05.004 PMID: 16876413

[12] Pornchai S, Chirappapha P, Pipatsakulroj W, Lertsithichai P, Vassanasiri W, Sitathanee C, Kongdan Y, Sukarayothin T, Leesombatpaiboon M. Malignant transformation of phyllodes tumor: a case report and review of literature. Clin Case Rep, 2018, 6(4):678-685. https://doi.org/10.1002/ccr3.1428 PMID: 29636939 PMCID: PMC5889262

[13] Tan J, Ong CK, Lim WK, Ng CC, Thike AA, Ng LM, Rajasegaran V, Myint SS, Nagarajan S, Thangaraju S, Dey S, Nasir ND, Wijaya GC, Lim JQ, Huang D, Li Z, Wong BH, Chan JY, McPherson JR, Cutcutache I, Poore G, Tay ST, Tan WJ, Putti TC, Ahmad BS, lau P, Chan CW, Tang AP, Yong WS, Madhukumar P, Ho GH, Tan VK, Wong CY, Hartman M, Ong KW, Tan BK, Rozen SG, Tan P, Tan PH, 
Teh BT. Genomic landscapes of breast fibroepithelial tumors. Nat Genet, 2015, 47(11):1341-1345. https://doi.org/10.1038/ ng.3409 PMID: 26437033

[14] Tse GMK, Niu Y, Shi HJ. Phyllodes tumor of the breast: an update. Breast Cancer, 2010, 17(1):29-34. https://doi.org/ 10.1007/s12282-009-0114-z PMID: 19434472

[15] Mohd Ali NA, Nasaruddin AF, Mohamed SS, Wan Rahman WF. Ki67 and P53 expression in relation to clinicopathological features in phyllodes tumour of the breast. Asian Pac J Cancer Prev, 2020, 21(9):2653-2659. https://doi.org/10.31557/ APJCP.2020.21.9.2653 PMID: 32986365 PMCID: PMC7779430

[16] Wang H, Wang X, Wang C. [Prognostic analysis of benign, borderline and malignant phyllodes tumors of the breast] Zhonghua Zhong Liu Za Zhi, 2015, 37(12):923-927. PMID: 26887622

[17] Chia Y, Thike AA, Cheok PY, Yong-Zheng Chong L, Man-Kit Tse G, Tan PH. Stromal keratin expression in phyllodes tumours of the breast: a comparison with other spindle cell breast lesions. J Clin Pathol, 2012, 65(4):339-347. https://doi.org/10.1136/ jclinpath-2011-200377 PMID: 22259180

[18] Lee AHS. Recent developments in the histological diagnosis of spindle cell carcinoma, fibromatosis and phyllodes tumour of the breast. Histopathology, 2008, 52(1):45-57. https://doi. org/10.1111/j.1365-2559.2007.02893.x PMID: 18171416

[19] Krings G, Bean GR, Chen YY. Fibroepithelial lesions; the WHO spectrum. Semin Diagn Pathol, 2017, 34(5):438-452. https://doi.org/10.1053/j.semdp.2017.05.006 PMID: 28688536

[20] Loke BN, Md Nasir ND, Thike AA, Lee JYH, Lee CS, Teh BT, Tan PH. Genetics and genomics of breast fibroadenomas. J Clin Pathol, 2018, 71(5):381-387. https://doi.org/10.1136/ jclinpath-2017-204838 PMID: 29248888

[21] Ng CCY, Md Nasir ND, Loke BN, Tay TKY, Thike AA Rajasegaran V, Liu W, Lee JY, Guan P, Lim AH, Chang KTE, Gudi MA, Madhukumar P, Tan BKT, Tan VKM, Wong CY Yong WS, Ho GH, Ong KW; International Fibroepithelial Consortium, Yip GWC, Bay BH, Tan P, Teh BT, Tan PH. Genetic differences between benign phyllodes tumors and fibroadenomas revealed through targeted next generation sequencing. Mod Pathol, 2021, 34(7):1320-1332. https://doi. org/10.1038/s41379-021-00787-w PMID: 33727697

[22] Chang HY, Koh VCY, Md Nasir ND, Ng CCY, Guan P, Thike AA Teh BT, Tan PH. MED12, TERT and RARA in fibroepithelial tumours of the breast. J Clin Pathol, 2020, 73(1):51-56. https:// doi.org/10.1136/jclinpath-2019-206208 PMID: 31662438
[23] Wei J, Tan YT, Cai YC, Yuan ZY, Yang D, Wang SS, Peng RJ, Teng XY, Liu DG, Shi YX. Predictive factors for the local recurrence and distant metastasis of phyllodes tumors of the breast: a retrospective analysis of 192 cases at a single center. Chin J Cancer, 2014, 33(10):492-500. https://doi.org/10.5732/ cjc.014.10048 PMID: 25104281 PMCID: PMC4198752

[24] Wang Y, Zhang Y, Chen G, Liu F, Liu C, Xu T, Ma Z. Huge borderline phyllodes breast tumor with repeated recurrences and progression toward more malignant phenotype: a case report and literature review. Onco Targets Ther, 2018, 11: 7787-7793. https://doi.org/10.2147/OTT.S171714 PMID: 30464526 PMCID: PMC6223390

[25] Chen WH, Cheng SP, Tzen CY, Yang TL, Jeng KS, Liu CL, Liu TP. Surgical treatment of phyllodes tumors of the breast: retrospective review of 172 cases. J Surg Oncol, 2005, 91(3): 185-194. https://doi.org/10.1002/jso.20334 PMID: 16118768

[26] Onkendi EO, Jimenez RE, Spears GM, Harmsen WS Ballman KV, Hieken TJ. Surgical treatment of borderline and malignant phyllodes tumors: the effect of the extent of resection and tumor characteristics on patient outcome. Ann Surg Oncol, 2014, 21(10):3304-3309. https://doi.org/10.1245/s10434-01 4-3909-x PMID: 25034817

[27] Choi N, Kim K, Shin KH, Kim Y, Moon HG, Park W, Choi DH, Kim SS, Ahn SD, Kim TH, Chun M, Kim YB, Kim S, Choi BO, $\mathrm{Kim} \mathrm{JH}$. Malignant and borderline phyllodes tumors of the breast: a multicenter study of 362 patients (KROG 16-08). Breast Cancer Res Treat, 2018, 171(2):335-344. https://doi. org/10.1007/s10549-018-4838-3 PMID: 29808288

[28] Ogunbiyi S, Perry A, Jakate K, Simpson J, George R. Phyllodes tumour of the breast and margins: how much is enough. Can J Surg, 2019, 62(1):E19-E21. https://doi.org/10.1503/cjs.00 5718 PMID: 30694037 PMCID: PMC6351251

[29] Belkacémi $Y$, Bousquet G, Marsiglia H, Ray-Coquard I, Magné N, Malard Y, Lacroix M, Gutierrez C, Senkus E, Christie D, Drumea K, Lagneau E, Kadish SP, Scandolaro L, Azria D, Ozsahin M. Phyllodes tumor of the breast. Int J Radiat Oncol Biol Phys, 2008, 70(2):492-500. https://doi.org/10.1016/j. ijrobp.2007.06.059 PMID: 17931796

[30] Abe H, Teramoto A, Takei Y, Tanaka Y, Yoneda G. Malignant phyllodes tumor of the breast with rapid progression: a case report. Surg Case Rep, 2020, 6(1):308. https://doi.org/10. 1186/s40792-020-00986-8 PMID: 33284362 PMCID: PMC 7721958

\section{Corresponding author}

Anca Lucia Pop, Lecturer, MD, PhD, Department of Clinical Laboratory, Carol Davila University of Medicine and Pharmacy, 37 Dionisie Lupu Street, Sector 2, 020021 Bucharest, Romania; Phone +40745-009 910, e-mails: anca.pop@umfcd.ro, ancapop@hotmail.com 